\title{
NACIONALIDAD ESPAÑOLA DE LOS HABITANTES DEL SAHARA OCCIDENTAL. COMENTARIO A LA SENTENCIA DE LA AUDIENCIA PROVINCIAL DE BARCELONA, DE 11 DE NOVIEMBRE DE 2019.
}

\author{
SPANISH NATIONALITY OF THE INHABITANTS OF WESTERN \\ SAHARA. COMMENTARY TO THE JUDGMENT \\ OF THE PROVINCIAL HEARING OF BARCELONA, \\ FROM NOVEMBER 11, 2019.
}

\author{
Alfonso Ortega GiméneZ* \\ Profesor Contratado Doctor de Derecho internacional privado \\ Universidad Miguel Hernández de Elche \\ (acreditado a Profesor Titular de Universidad) \\ ORCID: 0000-0002-8313-2070
}

Recibido: 15.04.2020 / Aceptado: 06.05.2020

DOI: https://doi.org/10.20318/cdt.2020.5659

\begin{abstract}
Resumen: Desde la Sentencia del Tribunal Supremo de 28 de octubre de 1998 se ha venido entendiendo que la vía por la que pueden acceder a la nacionalidad española los naturales del Sáhara, que nacieron cuando este territorio era provincia española, es el reconocimiento por posesión de estado, señalado por el artículo 18 de nuestro Código Civil. En este sentido la Sentencia de la Audiencia Provincial de Barcelona, de 11 de noviembre de 2019, estima un recurso admitiendo la inscripción de la nacionalidad por posesión de la nacionalidad tomando en consideración las pruebas testificales y documentales aportadas por el apelante siendo todo ello prueba de que el demandante estaba en posesión tanto de la documentación general como de la concreta a la que se refiere la normativa además de otros documentos que acreditaban el ejercicio de actividades propias del nacional español, por lo que resulta probada "la posesión del estado de nacional español por el actor, así como su utilización continuada, durante diez años como mínimo", afirmando, en consecuencia, "la consolidación de la posesión de hecho de su nacionalidad española" por el señalado plazo y "conforme a la buena fe", tal y como establece el artículo 18 del Código Civil.
\end{abstract}

Palabras clave: nacionalidad española, reconocimiento por posesión de estado, recuperación de la nacionalidad, Sáhara.

\begin{abstract}
Since the Judgment of the Supreme Court of October 28, 1998, it has been understood that the way through which the natives of the Sahara, who were born when this territory was a Spanish province, can access Spanish nationality, is the recognition of state possession, indicated by article 18 of our Civil Code. In this sense, the Judgment of the Provincial Court of Barcelona, of November 11, 2019, considers an appeal admitting the registration of nationality for possession of the nationality taking into account the testimonial and documentary evidence provided by the appellant, all of which is proof of that the plaintiff was in possession of both the general and the specific documentation referred to in the regulations, in addition to other documents that accredited the exercise of activities proper to the Spa-
\end{abstract}

*alfonso.ortega@umh.es 
nish national, for which it is proven "the possession of the state of Spanish national by the actor, as well as its continued use, for at least ten years ", affirming, consequently, " the consolidation of the de facto possession of its Spanish nationality "for the aforementioned term and" in accordance with good faith ", such and as established in article 18 of the Civil Code.

Keywords: Spanish nationality, recognition for possession of state, recovery of nationality, Sahara.

Sumario: I. Planteamiento. II. Litigio principal. III. Adquisición de la nacionalidad española de los naturales del Sahara. IV. Consolidación de la nacionalidad española de los naturales del Sahara, conforme al artículo 18 del Código Civil. V. Valoración de la prueba practicada. VI. Consideraciones finales.

\section{Planteamiento}

1. La principal y más grave consecuencia del cuestionable modo en que se llevó a cabo la descolonización del Sáhara es que el territorio fue abandonado a su suerte, sin llegar a producirse una sucesión de Estados, lo que sitúa al Sáhara desde entonces y hasta nuestros días en una situación de indefinición en el plano internacional, siendo una de las consecuencias más graves que los saharauis carezcan de nacionalidad, porque ni pudieron optar en muchos casos por la nacionalidad española, a la vista de las duras condiciones del Decreto de 1976, ni pueden tener una nacionalidad propia porque el Sáhara no es todavía, al día de hoy, un Estado ${ }^{1}$. De este modo, se ha derivado en la apatridia de estos ciudadanos que un día fueron súbditos del Estado español. ${ }^{2}$ El caso del Sahara se viene considerando en la doctrina como un supuesto de descolonización atípica y nada satisfactorio en cuanto al procedimiento seguido y en cuanto al resultado alcanzado, con una clara responsabilidad del Estado español en esta cuestión. ${ }^{3}$

2. El régimen jurídico aplicable a la adquisición de la nacionalidad española se regula en el Real Decreto de 24 de julio de 1889 por el que se publica el Código Civil ${ }^{4}$ (en adelante, CC), que tiene que ser integrado, en cuanto a la previsión de los requisitos legalmente exigidos y que tienen que ser cumplidos para obtener la residencia con la disciplina prevista en la Ley Orgánica 4/2000, de 11 de enero, sobre derechos y libertades de los extranjeros en España y su integración social ${ }^{5}$. Respecto a los sefardíes debemos tener en cuenta la Ley 12/2015, de 24 de junio, en materia de concesión de la nacionalidad española a los sefardíes originarios de España ${ }^{6}$, por el cual se ha facilitado el acceso a la nacionalidad española a los sefardíes en nombre de la vinculación histórica a España. Para el desarrollo de la Ley 40/1975, de 19 de noviembre, sobre descolonización del Sáhara ${ }^{7}$ se aprueba el Real Decreto 2258/1976, de 10 de agosto, sobre opción de la nacionalidad española por parte de los naturales del Sahara ${ }^{8}$, en virtud del cual se concedió el plazo de un año para que estos pudieran optar por la nacionalidad española cumpliendo ciertos requisitos. El mismo Decreto dispone que, transcurrido el plazo de un año, quedan anulados los pasaportes y documentos de identificación personal concedidos por las autoridades españolas a los naturales del Sáhara que no ejerzan su derecho de opción. De este modo, se ha venido entendiendo que los

\footnotetext{
${ }^{1}$ Vid. J.L. Argudo Périz y J.J. Pérez Milla, "Vinculación nacional y nacionalidad de los habitantes de los territorios descolonizados del África española", en Acciones e Investigaciones Sociales, №. 1, 1991, pp. 167-202.

2 Vid. J. Soroeta Liceras, "La problemática de la nacionalidad de los habitantes de los territorios dependientes y el caso del Sáhara Occidental”, en Anuario Español de Derecho Internacional, vol. XV, 1999, pp. 655 a 633.

3 Vid. C. Ruiz Miguel, "Nacionalidad española de ciudadanos saharauis: Secuela de una descolonización frustrada (y frustrante)", en Revista General de Derecho, No 663, 1999, pp. 14237 y 14238.

${ }^{4}$ Real Decreto de 24 de julio de 1889 por el que se publica el Código Civil (Gaceta de Madrid núm. 206, de 25 de julio de 1889).

${ }^{5}$ Ley Orgánica 4/2000, de 11 de enero, sobre derechos y libertades de los extranjeros en España y su integración social (BOE núm. 10, de 12 de enero de 2000).

${ }^{6}$ Ley 12/2015, de 24 de junio, en materia de concesión de la nacionalidad española a los sefardíes originarios de España (BOE núm. 151, de 25 de junio de 2015).

${ }^{7}$ Ley 40/1975, de 19 de noviembre, sobre descolonización del Sáhara (BOE núm. 278, de 20 de noviembre de 1975).

${ }^{8}$ Real Decreto 2258/1976, de 10 de agosto, sobre opción de la nacionalidad española por parte de los naturales del Sahara (BOE núm. 23, de 28 de septiembre de 1976).
} 
saharauis que no hubieran ejercido el derecho de opción establecido en el Decreto 2258/1976 carecerían de la nacionalidad española. A pesar de ello, se ha solicitado en numerosas ocasiones el reconocimiento o la recuperación de la nacionalidad española por parte de saharauis que no hicieron uso de este derecho de opción, particularmente con relación a personas que no se encontraban en situación de poder optar durante el plazo de un año establecido en el Decreto porque ni se encontraban en territorio español ni en territorio extranjero, por hallarse en el Sáhara, hecho que se aprecia en la Sentencia de la Audiencia Provincial de Barcelona de 11 de noviembre de 2019, objeto de estudio el cual estima el recurso presentado y reconoce la nacionalidad española en base al artículo 18 del CC. ${ }^{9}$

\section{Litigio principal}

3. La Sentencia de la Audiencia Provincial de Barcelona de 11 de noviembre de 2019 estima un recurso de apelación interpuesto contra una sentencia del Juzgado de Primera Instancia y revoca la Resolución de la Dirección General de los Registros y del Notariado (en adelante, DGRN) ${ }^{10}$, de fecha 22 de julio de 2014, por consiguiente, ordena la inscripción del solicitante como español por haber consolidado la nacionalidad española en los términos exigidos por el artículo 18 del CC.

El recurso de apelación se alza contra la desestimación por parte del Juzgado de Primera instancia $\mathrm{n}^{\circ} 39$ de Barcelona, el cual señala que no resultaban acreditados los datos esenciales como ser la filiación, fecha y lugar de nacimiento para practicar la inscripción de nacimiento, en tanto que la certificación emitida por la República Árabe Saharaui Democrática no constituye título suficiente por no provenir de un registro extranjero "regular y auténtico". Contra esta desestimación Don Casiano interpone recurso de apelación argumentando que la DGRN en Resoluciones de 24 de noviembre de 2015, 16 de enero de 2016 y 18 de enero de 2016 ha reconocido el valor probatorio de la documentación emitida por la República Árabe Saharaui Democrática respecto a los certificados de nacimiento y de antecedentes penales en dichos procesos. Por tanto, los certificados emitidos por la República Árabe Saharaui Democrática tienen valor probatorio respecto a los cuales se tiene constancia que el demandante nació en fecha NUM000 de 1975 en Villa Cisneros, situada en el Sáhara Occidental, actualmente denominada Dajla y que el pasaporte argelino del cual dispone no le libera de su condición de apátrida puesto que le fue facilitado por razones humanitarias para poder desplazarse en busca de formación y trabajo. Argumenta que reside en territorio español desde de 24 de diciembre de 2000, que tiene más de 12 años de cotización a la Seguridad Social, habiéndosele convalidado su título de Licenciado en Economía por una universidad de Cuba, que posteriormente ha realizado un curso de postgrado en la Universidad de Oviedo. Señala que ostentaba la nacionalidad española de origen por haber nacido en territorio español de padre y madre españoles de origen, por lo que tiene el derecho a optar por la nacionalidad española conforme al artículo $20.1 \mathrm{~b}$ ) del CC. La resolución impugnada le condena de facto a la apatridia tal y como se ha señalado en la Sentencia 3538/2015, de 9 de octubre de 2015 de la Audiencia Nacional, por lo que solicita que se revoque la resolución de la DGRN y que se acuerde la inscripción principal de la nacionalidad española a su favor en el Registro Civil Central, subsanando el error de la fecha de nacimiento anotada marginalmente en el expresado Registro que es la de NUM000 de 1975 y no la de 4 de junio de 1974 como erróneamente consta.

4. La DGRN se opone a la demanda argumentando que no corresponde la inscripción por la vía que se planteó en el procedimiento administrativo que se fundamentaba exclusivamente en el artículo

\footnotetext{
9 Vid., en sentido amplio, A. AlvÁRez Rodríguez, "Nociones básicas de Registro Civil y problemas frecuentes en materia de nacionalidad”, Ediciones GPS, Madrid, 2015; A. Ortega Giménez, (Dir.) y L. Heredia SÁnchez, (Coord.), "Manual práctico Orientativo de Derecho de la Nacionalidad", Editorial Thomson Reuters Aranzadi, Cizur Menor (Navarra), 2017; y J.C. Alonso BuRÓn, (Dir.), A. Ortega Giménez, (Coord.) y otros, “Código básico de Extranjería y Nacionalidad”, Ediciones Laborum, Murcia, 2007.

${ }^{10}$ Hoy día, denominada "Dirección General de Seguridad Jurídica y Fe Pública". Vid. Real Decreto 139/2020, de 28 de enero, por el que se establece la estructura orgánica básica de los departamentos ministeriales (BOE núm. 25, de 29 de enero de 2020), en relación con el Real Decreto 453/2020, de 10 de marzo, por el que se desarrolla la estructura orgánica básica del Ministerio de Justicia, y se modifica el Reglamento del Servicio Jurídico del Estado, aprobado por el Real Decreto 997/2003, de 25 de julio (BOE núm. 63, de 12/03/2020).
} 
18 del CC, por lo que no pueden ser objeto del presente litigio, las pretensiones ahora expuestas por el actor sobre su derecho a optar por la nacionalidad española. Según certificación de la Embajada de Argelia el demandante nació en Orán, por lo que no cumple la premisa indicada en la normativa, pero aun admitiendo que hubiera nacido en Villa Cisneros y no en Argelia, tampoco queda demostrado que el demandante residiera en el territorio ocupado (Sahara) en el año siguiente a la entrada en vigor del Real Decreto de 1976, por lo que no queda acreditado que el interesado o sus padres no pudieran optar por la nacionalidad española. Por consiguiente, el juzgado de instancia dictó sentencia desestimando la demanda al considerar que no se había acreditado que el demandante hubiera nacido en Villa Cisneros (actual Dajla), y que no obraban en autos elementos de juicio suficientes para considerar cumplido el requisito relativo a la utilización y posesión de la nacionalidad española durante 10 años.

5. Frente a esa resolución, el Señor Casiano presenta recurso de apelación, aportando pruebas testificales y documentales que demuestran que posee la nacionalidad española, acreditando el nacimiento en territorio español y la consiguiente inscripción en el registro civil que España llevaba en el Sáhara Occidental. Hechos que demuestran que el demandante ha actuado como español y no pudo ejercitar la opción a la que se refiere el real Decreto 2256/1976 por razones de edad y por hallarse en un campo de refugiados, además queda acreditado que sus padres han cotizado durante varios años a la seguridad social española provistos de DNI emitido por España para los ciudadanos del Sahara Occidental. Por tanto, el Tribunal estima el recurso de apelación, revoca la resolución de la DGRN y ordena que se proceda a la inscripción del solicitante, reconociendo su condición de español por haber consolidado la expresada nacionalidad española en los términos exigidos por el artículo 18 del CC.

\section{Adquisición de la nacionalidad española de los naturales del Sahara}

6. El concepto de nacionalidad, puede ser interpretado en un sentido negativo o formal, o bien como vínculo político jurídico que liga a un individuo con un determinado Estado. La pertenencia a una nación determina la condición de ciudadano y, como tal, le corresponde el ejercicio de derechos y cumplimiento de deberes, atribuidos o concedidos discrecionalmente por el Estado. La nacionalidad es reconocida como un estado civil, que se compone de una connotación personal que incide directamente en la capacidad de obrar de las personas, los acompaña desde su nacimiento y afecta sus leyes más personales, y a la que se une una connotación política por su carácter constitucional, que se encuentra reflejado en el artículo 13 de la Constitución española ${ }^{11}$ (en adelante, CE), aunque sea el CC el que lo regule sustancialmente.

Para determinar la condición de nacional desde la perspectiva constitucional del ordenamiento jurídico es preciso acudir al Capítulo Primero de la CE en la que no se equipara a nacionales y extranjeros como se deduce en el artículo 13.1 de la CE y que ha de ser interpretado junto con los artículos 10 y 53.1 de la $\mathrm{CE}^{12}$. Los Estados tienen competencia exclusiva en la regulación de la nacionalidad, pero limitada a la protección de la relación efectiva entre el Estado y sus nacionales y, en caso de que se verifique el fenómeno sucesorio, el Estado que sucede puede aprobar medidas legislativas que reconozcan la continuidad de la vinculación con el Estado sucedido.

7. Se pueden distinguir dos formas de adquisición de la nacionalidad española que son la originaria y la derivativa. La primera determina la adquisición de la nacionalidad desde el nacimiento y la segunda con posterioridad al mismo ${ }^{13}$. La nacionalidad española por origen se adquiere por la pertenencia del nacido a una determinada línea o estirpe familiar, ius sanguinis, o en virtud del lugar de nacimiento, ius soli. La adquisición de la nacionalidad española derivativa permite a personas, que en origen tenían

\footnotetext{
${ }^{11}$ Constitución Española (BOE núm. 311, de 29 de diciembre de 1978).

${ }^{12}$ De acuerdo con el artículo 13.1 CE: "Los extranjeros gozarán en España de las libertades públicas que garantiza el presente Título en los términos que establezcan los tratados y la ley".

13 Vid. J. M Maspinar Vicente, "La nacionalidad y la extranjería en el sistema jurídico español”, Civitas, Madrid, 1994, pp.72 y ss.
} 
otra nacionalidad o carecían de nacionalidad alguna, por la que ejercen el derecho a adquirir la nacionalidad tras la verificación de unas condiciones excepcionales determinadas legalmente. Se distinguen los siguientes modos: opción (= artículo 20.1 del CC), carta de naturaleza (= artículo 21.1 del CC) y residencia (= artículos 21.2 y 22 del CC). Además, se debe tener en cuenta la consolidación por posesión de estado previsto en el artículo 18 del CC.

8. Los naturales del Sáhara, que acrediten los requisitos legales exigibles, pueden acceder a la nacionalidad española de acuerdo con los siguientes títulos de atribución:

\section{a) Derecho de opción a la nacionalidad española}

La Ley de descolonización de 19 de noviembre de 1975 fue acompañada en su desarrollo normativo por el Decreto 2258/1976, de 10 de agosto, que reconoció el derecho de optar por la nacionalidad española a los naturales del Sahara que: a) se encontrasen en tal fecha residiendo en territorio nacional y estuviesen provistos de "documentación general española"; o bien b) que encontrándose fuera del territorio nacional español se hallaran en posesión de pasaporte español o estuvieran incluidos en los Registros de las representaciones españolas en el extranjero ( = artículo 1), lo que podían hacer en el plazo de un año a partir de la entrada en vigor del Derecho, mediante comparecencia ante el Encargado del Registro civil de su residencia (= artículo 2). Las actas levantadas de aquellas comparecencias ante el Encargado del Registro Civil recogiendo la manifestación de voluntad de optar y la acreditación de la posesión de la documentación requerida en cada caso daba lugar a las correspondientes inscripciones en los Registros civiles españoles con pleno reconocimiento de la nacionalidad española de los optantes.

\section{b) Adquisición de la nacionalidad española por residencia}

El artículo 22.2.a) del CC establece el plazo de residencia de un año respecto del que "haya nacido en territorio español". En este caso el debate jurídico se ha centrado en la correcta interpretación de la expresión "territorio español" utilizada por tal precepto. Así se entiende que el nacido en los antiguos territorios del Sahara español durante el periodo de dominación española del mismo cumple tal requisito, por lo que puede acceder a la nacionalidad española mediante residencia legal abreviada de un año.

\section{c) Consolidación de la nacionalidad española}

Dispone el artículo 18 del CC, "La posesión y utilización continuada de la nacionalidad española durante diez años, con buena fe y basada en un título inscrito en el Registro Civil, es causa de consolidación de la nacionalidad, aunque se anule el título que la originó". En este sentido se pronuncia la Sentencia de la Audiencia Provincial de Barcelona, de 11 de noviembre de 2019 que estima un recurso y ordena que se proceda a la inscripción del solicitante, nacido en Villa Cisneros en 1975, reconociendo su condición de español por haber consolidado la expresada nacionalidad española en los términos exigidos por el artículo 18 del CC.

\section{d) Atribución de la nacionalidad española iure soli en evitación de situaciones de apatridia}

En base a la interpretación del artículo 17.1.c) del CC que considera españoles de origen a "los nacidos en España de padres extranjeros, si ambos carecieren de nacionalidad o si la legislación de ninguno de ellos atribuye al hijo una nacionalidad". Teniendo en cuenta que no está por el momento reconocida internacionalmente la nacionalidad saharaui, cuando el padre del nacido en España, aunque haya estado con anterioridad en posesión de pasaporte argelino, haya sido desposeído de éste y actualmente 
esté documentado en España como apátrida, y cuando la madre, si bien está en posesión de pasaporte argelino, no es considerada ciudadana argelina por las autoridades de este país y así se acredita mediante certificación consular, hay que concluir que los padres son apátridas, de modo que se impone la atribución de la nacionalidad española iure soli al hijo.

\section{Consolidación de la nacionalidad española de los naturales del Sahara, conforme al artículo 18 del Código Civil}

9. En el Preámbulo de la Ley 18/1990, de 17 de diciembre, sobre reforma del Código Civil en materia de nacionalidad ${ }^{14}$ que reformó el artículo 18 se indica que la finalidad de darle nueva redacción al precepto era "evitar cambios bruscos y automáticos de la nacionalidad de una persona", por esta razón y para evitar este resultado se introduce una nueva forma de adquisición de la ciudadanía española por posesión de estado, lo que no es una novedad en Derecho comparado europeo. Tal posesión requiere las condiciones tradicionales de justo título, prolongación durante cierto tiempo y buena fe. A propósito de esta cuestión la Sentencia de la Audiencia Provincial de Barcelona de 11 de noviembre de 2019, reconoce la nacionalidad española del demandante en base a la posesión y utilización continuada de la nacionalidad española, condiciones que han sido probadas de sobra en el recurso interpuesto por el demandante.

10. La correcta interpretación y aplicación del artículo 18 del CC a la Sentencia de la Audiencia Provincial de Barcelona de 11 de noviembre de 2019, debe efectuarse en el especial contexto histórico referido a los naturales del denominado Sahara español y a la ulterior desvinculación del territorio de la metrópoli tras su ocupación por un tercer Estado. Al respecto la STS 1026/1998 de 26 de octubre de 1998 efectúa una síntesis histórica de los hechos indicados señalando lo siguiente: "El origen de la cuestión debatida se halla en las confusiones creadas por la legislación interna, promulgada para la antigua colonia del llamado Sahara español, en el período histórico precedente a la "descolonización" llevada en su día a cabo, en trance lleno de dificultades, que culminaron con el abandono del territorio, al margen, desde luego, de la calificación objetiva que mereciera el territorio del Sahara en relación con el territorio metropolitano, según el Derecho Internacional. Tal periodo histórico ha sido denominado, doctrinalmente, etapa de la "provincialización", a consecuencia de la manifestada y reiterada voluntad legislativa de equiparar aquel territorio, no obstante sus peculiaridades, con una "provincia" española, y, por ello, a considerarla, como una extensión del territorio metropolitano, o sea, territorio español, sin acepciones, con todas las vinculaciones políticas determinantes de la referida concepción que, sin duda, se proyectaron, como corolario obligado, en la población saharaui y, en su condición de nacionales españoles. Ilustres administrativistas enseñaron que la "provincialización" elevaba dichos territorios al rango de territorio nacional. Entre otras normas debe destacarse la Ley de 19 de abril de 1961 que estableció "las bases sobre las que debe asentarse el ordenamiento jurídico de la Provincia del Sahara en sus regímenes municipal y provincial", con otros aspectos, algunos tan importantes como el recogido en el artículo cuarto que, textualmente, dispone que "la provincia del Sahara gozará de los derechos de representación en Cortes y demás organismos públicos correspondientes a las provincias españolas", regla que fue llevada a la práctica con la participación efectiva de representantes saharauis en las Cortes y en el Consejo Nacional. Como manifestación de esta posición el Aaiun "era una provincia española y la palabra España comprendía todo el territorio nacional"."

11. Al referirse en concreto a la nacionalidad de los saharauis durante el tiempo en el que se prolongó la tutela española sobre el territorio del Sáhara, la expresada Sentencia concluye que esta nacionalidad fue la española. Cuestión distinta es que una vez producida la ocupación del territorio por un tercer estado y consumada la desvinculación de España, las autoridades españolas del momento concedieran a los habitantes del territorio la posibilidad de optar formalmente por la nacionalidad española, a

${ }^{14}$ Ley 18/1990, de 17 de diciembre, sobre reforma del Código Civil en materia de nacionalidad (BOE núm. 302, de 18 de diciembre de 1990). 
cuyo efecto se emitió el Real Decreto 2258/1976, de 10 de agosto, pero ello no significa que quienes no pudieron de facto ejercitar tal opción por hallarse en los campos de refugiados de Argelia y no tener posibilidad de acceder a un consulado español, no puedan acreditar su condición de originarios del Sáhara y a que les sea reconocida la nacionalidad española.

En la Sentencia de la Audiencia Provincial de Barcelona de 11 de noviembre de 2019 se aprecia el análisis de la aplicación del artículo $18 \mathrm{del} \mathrm{CC}$, al respecto el Tribunal señala que este artículo establece el concepto de consolidación de la nacionalidad por la posesión y utilización continuada de ésta, de acuerdo con el cumplimiento de determinados requisitos, así como la concurrencia de tractatus y fama, por lo cual en base a todas las pruebas presentada en autos se da por probada la inscripción en el Registro civil correspondiente, a pesar de que no se aportó la certificación correspondiente porque considera que "la existencia de la referida inscripción se produce con toda certeza, según la prueba practicada y según la legislación aplicable". Cierto que en la indicada resolución el Tribunal analiza un supuesto de anotación de la nacionalidad española con valor de simple presunción, pero la doctrina que expone ha de ser de igual aplicación al caso que ahora nos ocupa en que al demandante ya le fue anotada la nacionalidad española con valor de simple presunción y lo que se analiza es si la anotación de nacimiento que sirvió de soporte a la anotación de presunción de la nacionalidad española, puede convertirse en una inscripción definitiva en base al artículo 18 del CC.

12. En consecuencia el acceso a la nacionalidad española por la vía del artículo $18 \mathrm{CC}$ se aplicaría a los naturales del Sáhara que tuvieron inscrito su nacimiento en España y vieron anulado su título en virtud de la Ley 40/1975 sobre descolonización del Sahara y el Real Decreto 2258/1976 por no ejercer la opción prevista en este último porque, no pudieron hacerlo, perteneciendo, así, al tertium genus. El Ministerio de Justicia a través de la DGRN, ha venido reconociendo la consolidación de la nacionalidad española cuando el interesado en el expediente registral instruido acredita que reúne las condiciones exigidas para la consolidación, esto es, inscripción en el Registro Civil español, prueba de la posesión y utilización de la nacionalidad española durante diez años, bastando para ello haber ostentado documentación oficial española vigente durante tal periodo de tiempo, y haber estado imposibilitado de facto para el ejercicio de la opción concedida por el Decreto de 10 de agosto de 1976 durante el año de vigencia de la misma por haber residido durante dicho periodo en el Sahara ocupado por Marruecos. Por tanto, ha quedado admitido que la citada población pueda adquirir la nacionalidad española por posesión de estado prevista en el actual artículo 18 del Código Civil, si bien, en este supuesto incumbe al demandante la carga de probar que reúne los requisitos establecidos en tal precepto.

13. En la Sentencia de la Audiencia Provincial de Barcelona de 11 de noviembre de 2019, con el fin de probar que el demandante reúne los requisitos necesarios para la consolidación de la nacionalidad española se pone de manifiesto el relato proporcionado por la testigo Doña Miriam que manifestó ser prima del demandante, quien explicó que su familia y la del actor residían en Villa Cisneros, y que junto a otros miles de personas debieron trasladarse a los campamentos de refugiados de Tinduf en el año 1976, indicando que "todos" terminaron en los campos y que desde allí salieron a estudiar a Cuba, tanto la propia testigo como el actor, viniendo posteriormente a España en el año 2005, indicando que el actor regreso unos años antes. Tomando en consideración las pruebas aportadas en los autos y la declaración testifical de la testigo la sala señala que el demandante ha actuado como español porque nació en territorio español, y no pudo por razones de edad y por hallarse en un campo de refugiados, ejercitar la opción a que se refiere el real Decreto 2256/1976, de 10 de agosto, debiendo asimismo tener en cuenta para explicar esta consideración propia como español, el hecho de que su padre estuviera dado de alta en el sistema de la Seguridad Social española como de nacionalidad española, así como que su madre dispusiera del DNI emitido por España para los ciudadanos del Sahara Occidental. Obra en autos documentación que acredita que el actor estudió en la universidad cubana de Camagüey en la que obtuvo el título de Licenciado en Economía en julio de 1998, y que posteriormente se trasladó a España, donde siguió un programa de doctorado en la Universidad de Oviedo durante los cursos 2001/2002 2002/2003, 2004/2005 y 2005/2006 habiéndose certificado en fecha 29 de septiembre de 2005, por la Directora de la Residencia "Ramón Menéndez Pidal", que el ahora demandante residió en el centro desde el 25 de 
julio de 2003 hasta la culminación de sus estudios, extremo que acredita suficientemente su presencia en España desde el año 2001. Todo ello es prueba de que el demandante estaba en posesión tanto de la documentación general como de la concreta a la que se refiere el Decreto, además de otros documentos que acreditaban el ejercicio de actividades propias del nacional español, por lo que resulta probada "la posesión del estado de nacional español por el actor.

\section{Valoración de la prueba practicada.}

14. En relación con el valor probatorio de la documentación aportada por los ciudadanos saharauis, expedida por la República Árabe Saharaui Democrática (en adelante RASD) se ha producido un cambio de criterio a raíz del informe emitido por el entonces Ministerio de Asuntos Exteriores y Cooperación de fecha 5 de octubre de 2015, en relación con los certificados de nacimiento y de antecedentes penales señala que la falta de reconocimiento por parte de España de la RASD o la falta de definición del estatuto internacional del Sáhara no afectan per se al valor probatorio de los documentos emitidos por sus autoridades; en particular, por lo que hace a los certificados de nacimiento y de antecedentes penales. Por lo cual no existen obstáculos en el Derecho Internacional para admitir tales certificaciones en los expedientes de solicitud de la nacionalidad española ante las autoridades registrales de España.

15. En este sentido en la Sentencia de la Audiencia Provincial de 11 de Noviembre de 2019, consta aportada a los autos copia de la solicitud inicial del demandante ante el Encargado del Registro Civil de Santa Coloma de Gramanet para que se anotara con valor de simple presunción que ostentaba la nacionalidad española, solicitud que como hemos explicado, le fue efectivamente reconocida, y en la que refiere adjuntar una serie de documentos como el "Certificado expedido por el Juzgado Cheránico de Atín (Sahara) del Archivo General de la Administración- Alcalá de Henares”, lo que supone que acompañó una prueba documental emitida por un Registro público español, puesto que en el Archivo General de la Administración a que nos hemos referido, creado por Decreto 914/1969, de 8 de mayo, se custodian, entre otros documentos, los producidos por la Administración colonial en África, en particular, y por lo que aquí interesa, los denominados "libros cheránicos", es decir, aquellos que de forma incompleta fueron salvados al abandonar España el territorio del Sáhara Occidental y que contenían los datos del estado civil de sus residentes autóctonos. El tribunal señala que los documentos aportados ha de tener valor suficiente para acreditar el lugar de nacimiento, puesto que este era el modo utilizado por la Administración colonial española para registrar los nacimientos de los lugareños. Consta que la parte actora aportó certificación emitida por la República Árabe Saharaui Democrática en el sentido de que el peticionante nació en Villa Cisneros (Sáhara Occidental), y si bien es cierto que tal entidad no ha sido formalmente reconocida como un Estado propio e independiente, con las evidentes consecuencias que ello comporta para el reconocimiento de las certificaciones o documentos emitidos. Finalmente, el solicitante esta referenciado en el registro efectuado por la Misión de las Naciones Unidas para el referéndum del Sáhara Occidental (MINURSO) como nacido en Dajla (antigua Villa Cisneros) en el año 1975.

16. Además, el Tribunal señala que la prueba de nacimiento y el pasaporte argelino en el que figura que nació en Orán (Argelia) el día NUM000 de 1974, no es acreditativo de que ostente la nacionalidad argelina. En primer lugar, porque el propio país que emitió el pasaporte en fecha 6 de febrero de 2008, a través de su Embajada en Madrid, señala que el ciudadano Casiano es de origen saharaui y no tiene la nacionalidad argelina, a pesar de que indica que nació en Orán el NUM000 de 1974, manifestación que fue reiterada por certificado de 22 de noviembre de 2017 de la expresada Embajada, en respuesta a la Diligencia acordada por el juzgado de instancia. Al respecto la jurisprudencia de los tribunales de lo contencioso administrativo ha reiterado que la concesión del pasaporte argelino a ciudadanos de origen saharaui responde a razones de carácter humanitario, sirviendo de ejemplo, la Sentencia del Tribunal Supremo que señala que el otorgamiento del pasaporte "consiste en proceder a documentar a quien por diversos motivos carece de documentación que le impide su simple desplazamiento e identificación", y que "cuenta con un carácter formal, no exige la solicitud y voluntariedad del destinatario y no implica 
una relación de dependencia con el Estado documentante". De ahí que, en definitiva, si el solicitante no ostenta la nacionalidad argelina denegarle la posibilidad de ser considerado español seria abocarle a una situación de apatridia. Tomando en consideración lo expuesto el Tribunal manifiesta que el demandante ha acreditado que nació en Villa Cisneros (Sáhara Occidental) en el año 1974, y no en 1975, como erróneamente se recoge en el Registro Civil Central, lo que significa que nació en un territorio que en aquel momento podía considerarse territorio español, por lo que estima la pretensión del demandante discrepando de la conclusión de la DGRN, y que sobre la base de las pruebas aportadas se ha consolidado la nacionalidad española en los términos del artículo 18 del CC.

\section{Consideraciones finales}

17. Durante la época del colonialismo europeo iniciada en el siglo XIX y prolongada durante la primera mitad del siglo XX, el territorio del Sáhara quedó bajo la dominación española, situación que se mantiene hasta que la Ley 40/1975, de 19 de noviembre sobre descolonización del Sáhara pone fin a la misma para dar cumplimiento a lo dispuesto en la resolución 1514 (XV) de la Asamblea General de Naciones Unidas de 14 de diciembre de 1960 sobre la concesión de independencia a los países y pueblos coloniales. El caso del Sahara se viene considerando en la doctrina como un supuesto de descolonización atípica y nada satisfactorio por las formas en que se realizó.

A la vista de todo lo expuesto, parece que podrían encontrarse argumentos de peso para reconocer que los naturales del Sahara que nacieron cuando este territorio estaba bajo administración española tuvieron en aquel momento la nacionalidad española, hasta que, en un momento posterior, con la Ley 40/1975 y el RD 2258/1956, quedaron privados de tal nacionalidad por no ejercer el derecho de opción que preveía el Real Decreto. Este planteamiento, sin embargo, es contrario a la postura que viene manteniendo la DGRN y no encuentra un claro respaldo en el ámbito judicial, porque la STS de 28 de octubre de 1998 reconoció el acceso a la nacionalidad por la vía del artículo 18 del CC, en el mismo sentido se estima el recurso interpuesto por el apelante en la Sentencia de la Audiencia Provincial de Barcelona de 11 de noviembre de 2019, que es objeto de análisis.

18. Si analizamos este tema desde la distancia que nos separa con la turbulenta descolonización, y en un Estado con principios constitucionales ya consolidados, se puede considerar que aquellos saharauis que nacieron en la etapa de provincialización fueron en su día nacionales españoles por lo que podrían recuperar la nacionalidad española si acreditan los requisitos legales exigibles, de acuerdo con los siguientes títulos de atribución: a) Derecho de opción a la nacionalidad española, establecido por la Ley de descolonización de 19 de noviembre de 1975 que reconoció el derecho de optar por la nacionalidad española a los naturales del Sahara que se encontrasen en tal fecha residiendo en territorio nacional y estuviesen provistos de "documentación general española"; o bien que encontrándose fuera del territorio nacional español se hallaran en posesión de pasaporte español o estuvieran incluidos en los Registros de las representaciones españolas en el extranjero, lo que podían hacer en el plazo de un año a partir de la entrada en vigor del Decreto, mediante comparecencia ante el Encargado del Registro civil de su residencia; b) Adquisición de la nacionalidad española por residencia, en base al artículo 22.2.a) del Código Civil el cual establece el plazo de residencia de un año respecto del que "haya nacido en territorio español"; c) Consolidación de la nacionalidad española, según lo dispuesto en el artículo 18 del CC.

En este sentido se pronuncia la Sentencia de la Audiencia Provincial de Barcelona, de 11 de noviembre de 2019 que estima el recurso de apelación interpuesto y revocando una Resolución de la DGRN de 22 de julio de 2014, por lo que ordena que se proceda a la inscripción del solicitante, nacido en Villa Cisneros en 1975, reconociéndole su condición de español por haber consolidado la expresada nacionalidad española en los términos exigidos por el artículo 18 del CC.

Y, por último, en base a la interpretación del artículo 17.1.c) del CC que considera españoles de origen a "los nacidos en España de padres extranjeros, si ambos carecieren de nacionalidad o si la legislación de ninguno de ellos atribuye al hijo una nacionalidad", la atribución de la nacionalidad española iure soli en evitación de situaciones de apatridia. 